\title{
V Jornadas Nacionales de Estudios Ecuménicos
}

\author{
Salamanca, 18 al 21 de abril, 1968
}

Organizadas por el Centro Ecuménico Juan XXIII de la Universidad Pontificia de Salamanca se han tenido en esta ciudad las V Jornadas Nacionales de Estudios Ecuménicos. El tema central de estos días de estudio ha sido: El protestantismo a la luz del Vaticano II. Se trataba con ello de hacer notar, de algún modo, el 450 aniversario de la Reforma Luterana. La presencia de diversas personalidades protestantes y católicas ha contribuído notablemente a realizar estos días de estudio y a dar luz sobre puntos todavía cuestionables doctrinalmente, a pesar de la buena voluntad y los mejores esfuerzos de los estudios de ambas teologías: luterana y católica.

Por parte protestante tuvieron ponencias el célebre profesor Jean Luois Leuba, de la Universidad protestante de Neuchatel, quien dirigió tres conferencias, punto fuerte de las jornadas; el profesor Gutiérrez Marín, de Barcelona, y un pastor hispanoamericano, profesor del Centro de estudios ecuménicos de Bosey. Asimismo asistieron el Obispo de Taibó, de la Iglesia Evangélica Reformada española, y otros pastores protestantes. Por parte católica actuaron como confenenciantes el P. Argimiro Turrado, agustino, director de la Revista Agustiniana de Espiritualidad y profesor en el Estudio TeOLógico de Valladolid, eminente investigador de San Agustín y Lutero; el profesor Jedin, autoridad máxima en el Concilio de Tnento; el profesor García Suárez, de Pamplona, y el profesor González Martín, de Salamanca.

Asistieron medio centenar de profesores de Teología de los diversos puntos de España, algunos delegados diooesanos de ecumenismo y un reducido número de seminaristas y religiosas. Se hizo notar la ausencia de una buena parte de delegados diocesanos de Ecumenismo. $Y$ esto es lamentable, ya que demuestra que los contados intentos de diálogo ecuménico a escala nacional se ven recompensados por una apatía crónica, consecuencia del escaso valor científico e investigador de nuestro clero dinector. Es largo el camino a necorrer, el formar hombres con inquietudes serias dentro del campo doctrinal católico que sean capaces de exponer, 
con serenidad de juicio y conocimiento sensato, los graves problemas espirituales que van a dejarse sentir en la sociedad religiosa de un futuro inmediato. Se impone una labor profunda y seria, sacrificada y tenaz, para cambiar el panorama ecuménico español, para abrir los ojos de nuestras estructuras intelectuales al mensaje conciliar en todo su esplendor.

Las sesiones se abrieron el jueves, día 18 de abril, a las cuatro de la tarde, en la sede del Centro Ecuménico Juan XXIII. El pastor Antonio Puchadas, de Salamanca, leyó un trozo de la última parte del c. IV de la Canta a los Romanos. Acto seguido, D. José Sánchez Vaquero, director del Centro, dirigió unas palabras a los congresistas invitando al diálogo abierto de la caridad evangélica. Explicó cómo estas jornadas estaban dedicadas especialmente a conmemorar el 450 aniversario de la Reforma y a valorar las aportaciones legítimas que en ella podemos encontrar aún hoy. Fue presentando a cada uno de los ponentes, en especial al que a continuación había de tener la primera conferencia del ciclo, Dr. Gutiérrez Marín, presidente de la Iglesia Prresbiteriana española, hombre entendido en el diálogo ecuménico, formado en Centroeuropa, allí donde se están haciendo los mejores esfuerzos en el campo doctrinal para un posible acercamiento de bases ideológicas.

Estado aCtuAl del PRoblema de la JUStificación. Dr. Gutiérrez Marín. Obsevador del Vaticano II.

Comienza señalando el silencio habido en el último decenio sobre el problema de justificación en el diálogo ecuménico. Desde las aportaciones Hans Kung 7 Stechl ien 1957-1958, no se ha hecho nada en serio. La misma Alianza Luterana de 1963 fue incapaz de llegar a un acuendo y son muy pacos los que en la actualidad se enfrentan de lleno con esta temática. Para el Dr. G. Marín, la justificación, más que un problema confesional a resolver, es una cuestión antropolớgica-bíblica a ventilar. $\mathrm{Y}$ de este modo acentúa desde el principio un matiz eminentemente existencial del problema.

Justificación en la Reforma. Abarca una triple base: teológica, antropológica y cristológica. A primera vista se nota la ausencia del aspecto eclesiológico, en el que se insiste dentro de la doctrina católica. Para la Reforma está Dios, creador y santificador, el hombre que cae y Cristo Miediador, hombre muriente. Afronta a continuación el ponente la cuestión de la "fe sola" para la justificación dentro de los Reformadores. Aunque es verdad que Lutero, ni en su Catecismo Mayor ni en el Menor pone la justificación en la "sola fe", los otros grandes Reformadores insisten en la expresión "sola fe". Así lo encontramos en Melancton (Confesión de Ausburgo)! Calvino (Instituciones de Calvino) y en Zuinglio 
(Confesión Helvética posterior). La misma expresión aparece en el Catecismo de Heildelberg de 1563, llegando a la conclusión de que, dentro de la teología de los principales Reformadores, somos salvados exclusivamente por la fe.

Acerca de las soluciones doctrinales aparecidas durante la historia dentro de la teología protestante y católica, G. Marín insiste en que tales soluciones valen solamente por el momento y para el momento, acentuando un punto de vista eminentemente relativista, muy en consonancia con su postura protestante. Repite la necesidad de una idea vivencial de la justificación y la exigencia de llegar a una interpretación central de este tema, intenpretación que debe salir de tadas las Iglesias y que sirva para iluminar a este mundo y llevarle a la esperanza, sacándole de la angustia espiritual en que vive. Esto lleva consigo volver a examinar los troblemas de la naturaleza y de la gracia, lo cual exige una labor ímproba y ura disposición humilde por nuestra parte para ver "cómo Dios por Cristo nos ha servido a todos".

Coloquio.-Se hacía necesario a todas tuces el exponer con precisión y acierto la postura católica sobre este punto. Ello corrió por cuenta del P. Turrado, quien señaló cómo en la postura católica la justificación es algo más que esa "mera imputatio". La "imago Dei" que aparece en el Antiguo Testamento, en la teología paulina, en los Santos Padres, principalmente en San Agustín, queda en vendad deformada por el pecado. Pero con la justificación, con la gracia de Cristo, esa "imago" es reformada. Es cierto que la justificación primera no es experimentable, pero en católico también se habla de esa "secunda justificatio" experimentable que viene a ser la fiducia de los protestantes. El hacernos "conformes imagini plenitudinis Christi" exige que la justificación sea a la vez santificación, que el hombre se apropie esa acción crística. Con ello, según los Santos Padres, San Agustín y el Helenismo, el hombre recobrará la auténtica "imago Dei".

El Dr. G. Marín, a pesar de su mejor voluntad y de su gran esfuerzo no logró darnos una respuesta clara y concisa sobne el tema.

Los reformadores en la teología protestante aCtual. Por el Prof. Jean Louis Leuba, de la Universidad de Neuchatel.

Varias han sido, a través de la historia, las posturas tomadas por los teólogos protestantes frente a Reforma. Examina ligeramente la teología liberal, el modernismo y las corrientes luteranas, calvinista y radical de cierta importancia en nuestros días. Hace ver cómo Hegel y Kierkegaard juegan un papel importante en estos enfrentamientos y en las concepciones protestantes de la Iglesia y de la historia a través de los dos últimos siglos.

$\mathrm{La}$ vuelta a los Reformadores en la teología protestante actual está caracte- 
rizada por unos postulados, cuyos puntos más sobresalientes podrían ser los siguientes :

1. Tomar en serio el carácter último y definitivo de la epifanía de Cristo. Es preciso ante todo meter la Biblia en la vida de la Iglesia. Con esto quieren curtar el paso definitivamente a toda corriente modernista.

2. La fe como condición del conocimiento: Se impone buscar la exégesis uel credo para creer. No se trata talmente de buscar una inteligibilidad de la fe, aunque hay que intensificar el carácter existencial de esa misma fe. Con ello se evita de raíz todo racionalismo.

3. Aceptar el compromiso de la fe en que se nos muestra el carácter revelador de la bistoria de Cristo, atiestiguada por los apóstoles. $\mathrm{Y}$ hay que conjugar este conocimiento objetivo con ell conocimiento existencial. Con ello se echa por tierra el fideismo.

4. Aceptar con seriedad el carácter escatológico del evangelio. En este punto la teología monacal tiene mucho que decir a los teólogos.

Acentúa finalmente Leuba el carácter católico de la Reforma del siglo XVI, basándose en su sentido profético. Sin reste sentido profético la Reforma piende su punto de impacto. Los reformadores del siglo XVI se sienten metidos en la tradición eclesiástica bien entendida y no tienen conciencia de que estaban poniendo en marcha una nueva Iglesia. La consideración de cómo estaba, en la práctica, el elemento jerárquico da pie para una reforma, reforma que se dejaba sentir por doquier aún dentro del mundo latino.

El camino a seguir en busca de un entendimiento ecuménico sano y sincero no debe ser el de la aceptación pasiva de la división ni los anatema mutuos. Se impone, según el profesor de Neuchatel, la búsqueda en común para sobrepasar las oposiciones del pasado.

Coloquio.-Se centra en la acentuación de la postura antirracionalista de los protestantes. No faltó, por parte católica, alguien que, con cierta ligereza y excesivo irenismo, veía lógica esta postura. Fue de nuevo el $P$. Turrado el que hace ver cómo una benevolencia mal entendida en este punto puede conducir a la neegación del Vaticano I que diefiende que el hombre puede llegar a un conocimiento de Dios por las luces de la razón. Por eso, los protestantes nos cuentan entre los racionalistas. Además, insiste el $\mathrm{P}$. Turrado, rechazando el iluminismo y negando a la vez el magisterio necesariamente hay que ir a parar a un libre examen, donde el iluminado tiene que campar por su fueros. $Y$ es que el carisma profético, aún con su libertad, ha de estar bajo el control de la autoridad, como consta en San Pablo. 
Escritura y Tradición, CONFrontación ecuménica. Prof. Leuba.

Se reduce a examinar las relaciones existentes entre la Const. Dei Verbum del Vaticano II y el "Rapport" de la Conferencia de Fe y Constitución de Montreal, 1963.

Estudia:

a) Puntos convergentes. Tanto el Vaticano II como la Conferencia de Montreal admiten como fundamento la "epifanía histórica, única y definitiva de Cristo", ligada íntimamente a la historia de la salvación. Otro signo de contacto es la conexión estrecha entre Escritura y Tradición. Leuba juzga que es mejor hablar de Tradición y Escritura. El punto de convergencia es visto por el conferenciante en el una cum. La Escritura no es sin la Tradición y la Tradición no es sin la Escritura. En esta fórmula hay que centrar el punto de partida para un auténtico diálogo ecuménico. El camino seguido en ambas teologías para llegar a esta fórmula ha sido diferente. El catolicismo avanza desde el " $y$ " tridentino hasta el "una cum" del Vaticano II. El protestantismo ha pasado, por el contrario, de la "sola Scriptura" del siglo XVI hasta el "una cum" de los teólogos contemporáneos.

b) Cuestiones pendientes. Problema de la corexión entre la "ontología del Traditum y la noética del actus tradendi. ¿Cómo el actus tradendi (tradición) ilumina el Traditum (Escritura)? Problema del progreso de la tradición, admitido por el catolicismo y rechazado por las corrientes protestantes. Problema del magisterio, quizás el más serio intenrogante en este campo para Leuba, ya que no posee el sentido pleno del ministerio según lo entiende la Iglesia católica. A pesar de todo, propone unos puntos o perspectivas de investigación que quizás choquen a los mismos protestantes: "necesidad de un órgano para expesar el consensus de la Iglesia, infalibilidad solamente para las definiciones negativas, relatividad histórica de las definiciones positivas y confrontación constante entre el desarrollo dogmático y el mensaje de la Escritura". A pesar de todo ve la posibilidad de un diálogo abierto para llegar a unirnos en la búsqueda de soluciones.

\section{Católicos y Protestantes ante el mundo de hoy. Prof. Leuba.}

Las Iglesias cristianas están enfrentadas actualmente a una misma problemática planteada por el humanismo contemporáneo a la fe cristiana. Este humanismo rcviste dos aspectos fundamentales: un neopositivismo, humanismo científico y un humanismo marxista, desviación de la fe judeo-cristiana. 
Humanismo científico.-Reduce todo conocimiento a un conocimiento de tıpo objetivo. El hombre, al igual que las cosas, es simplemente un objeto para la psicología, sociología, medicina... Dios queda fuera de este conocimiento. Nace en Kant y sigue con Jung. La respuesta cristiana debe acentuar la esfera de la decisión ética, que es a la vez eminentemente humana y evangélica. Se impone reconocer el mundo de la libertad, del amor, de la conciencia, valores estos que quedan ahogados en la visión cerrada del humanismo científico. Examina después la otra vertiente Humanismo-marxista, desviación de la fe judeo-cristiana. Coincide con el cristianismo en reconocer la importancia histórica de Cristo y del Evangelio, que dan al hombre la posibilidad de hacer frente al mundo y de llevar a cabo una revolución en pro de la humanidad. Pero a la vez considera el evangelio como una fuerza pasada, histórica, incapaz de implicaciones actuales para ayudar al hombre a la solución de sus problemas, incapaz de transformar el mundo. Este cristianismo actual, según el marxismo, no responde a la llamada del evangelio y por tanto carece de interés. La respuesta de las iglesias cristianas ha de ser en primer lugar la de presentar el Evangelio de Cristo como fuerza viva y siempre actual que permite y obliga a la acción en el mundo hasta llegar a transformarlo. Transformación esta muy diferente, es verdad, de la transformación de tipo hegeliano en donde Marx y los suyos bebieron sus doctrinas. Por otra parte, hace ver Leuba cómo un examen existencial del marxismo nos lleva a la conclusión de que el marxismo aprisiona al hombre en la historia y en el mundo, negándole todo recurso a una transcendencia.

I.UTERo y SAN Agustín. P. Argimiro Turrado, agustino.

La charla del P. Turrado merecería un comentario amplio y detallado. En conjunto podríamos calificarla como un hermoso ensayo de antropología natural y sobrenatural dentro del pensamiento agustiniano, en donde tienen explicación los problemas de la justificación, concupiscencia, predestinación y eclesiología, problemas mail comprendidos por Lutero haciendo posible de esta manera la separación de Roma, con tan tristes consecuencias para $\mathrm{l}_{\mathfrak{a}}$ cristiandad. Dividió la exposición en cuatro puntos:

1. Pérdida de la imagen de Dios por el pecado.-En esta frase, usada con cierta frecuencia por San Agustín hasta el 408, se fundan Lutero, Calvino y otros muchos teólogos protestantes modernos para confirmar su doctrina fundamental de la corrupción radical de la naturateza humana por el pecado de origen. "La finalidad de San Agustín, dice el P. Turrado, es exponer el sentido sobrenatural, extrictamente paudino (Cristo-Adán, hombre viejo-hombre nuevo, hombre celestehombre terrestre) de esa expresión y el uso de la misma contra los maniqueos. 
$Y$ es a partir del 412, en su lucha contra los pelagianos, que negaban el pecado otiginal y el mal de la concupiscencia, cuando insiste San Agustín en las heridas naturales de la ignorancia y la concupiscencia desarreglada producidas por el pecado de origen con el fin de combatirles. Pero San Agustín nunca defendió la pérdida total de la imagen natural de Dios por el pecado".

2. Concupiscencia como "peccatum" en San Agustin.-"En los libros antipelagianos, San Agustín usa con cienta frecuencia una expresión, a primera vista comprometedora, para indicar los efectos del bautismo, es decir, el perdón del pecado original y de todos los demás pecados, pero permaneciendo la concupiscencia: tollitur reatus, manet peccatum. Los Refonmadores, defendiendo la justificación meramente extrínseca, admiten la permanencia del pecado original que sc identifica para ellos con la concupiscencia". Turrado hace ver cómo "la terminología de Agustín no corresponde a la terminología moderna. Agustín llama indistintamente a la concupiscencia peccatrum malum y poena peccati, insistiendo en esto porque los pelagianos no admitían ni la existencia del pecado original ni el mal de la concupiscencia. Y como la concupiscencia, castigo del pecado de origen, debilita las fuerzas de la voluntad y nubla en parte la luz de la rázón, para San Agustín todos los hombres tienen el pecatım, porque todos ellos están bajo los efectos de la concupiscencia".

La explicación de este modo de hablar la encuentra el P. Turrado en lo que expone a continuación: "La terminología ide San Agustín acusa siempre un neoplatonismo muy marcado, especialmente por su teoría de la participación, que implica a la vez la causalidad eficiente y ejemplar. Por eso la presencia de un efecto acusa la presencia de la causa eficiente y ejemplar del mismo, y causa y efecto reciben con frecuencia el mismo nombre. En este caso concreto la concupiscencia y la falta de caridad reciben el mismo nombre de peccatum; al igual que los ritos sacramentales del bautismo y del orden y su efecto, el carácter indeleble, reciben el mismo nombre de sacramentum". Todo ello hace ver cómo a San Agustín no se le puede interpretar a la luz de la filosofía y teología escolásticas, sin adulterar lamentablemente su pensamiento. El no captar esto con precisión y acierto es lo que dio pie a Lutero y a los. Reformadores para poner a San Agustín como defensor de sus doctrinas y maestro de sus enseñanzas.

3. Predestinación.-He aquí un punto de suma importancia dentro de la doctrina de los Reformadores. "Es bien conocida la interpretación de Lutero, el cual prefiere prescindir del Deus absconditus para refugiarse en el Deus revelatus, en Cristo. De este modo, por la fe fiducial, podemos percibir con certeza que los fensamientos de Dios sobre nosotros son de justicia y de paz, y no de temor y de aflicción, podemos percibir con certeza nuestra predestinación. Calvino, por el contrario, tiene una interpretación mucho más dura, lógica y desesperante. No admite ni la certeza de que nuestra fe fiducial sea auténtica ni, por lo mismo, la 
certeza de nuestra predestinación, que depende únicamente del decreto eterno y fijo de Dios sin atención a los méritos o deméritos del hombre".

$\mathrm{Y}$ no han faltado voces, aún dentro del campo católico, que han querido ver esa misma doctrina en los libros científicos de San Agustín, como el benedictino Rottmanner. Y algo parecido ha afirmado recientemente Boublick. Las respuestas, poniendo las cosas en su sitio, han venido inmediatamente, en especial por parte de J. Morán, A. Sage y A. Trapé. "Aquí sólo haremos notar, termina el P. Turrado, que todo el que desee comprender la doctrina de San Agustín en torno a la predestinación debe reducir la cuestión al problema de la gracia. Si no se comprende bien su doctrina sobre la reforma de la imagen divina del hombre, sobre todo tal como la expone en los últimos libros del De Trinitate, se corre el peligro de atribuirle una serie ininterrumpida de contradicciones. Al fin, el resumen de su doctrina será siempre éste: Qui ergo fecit te sine te, non te iustificat sine te"

4. Eclesiología de San Agustín.-Otro punto de máximo interés en la confrontación ecuménica. La acentuación del carácter pneumático y espiritual de la Iglesia defendido en la postura protestante, en contra del carácer ministerial y jerárquico de la concepción católica ha sido a través de la historia ocasión de múltiples disputas. Una interpretación auténtica de la doctrina agustiniana podría esclarecer este problema, tal como lo ha hecho el Concilio Vaticano II. "San Agustín, dice el $\mathrm{P}$. Turrado, tiene una doble concepción de la Iglesia o Cuerpo de Cristo: a soteriológica, y en este sentido pertenecen a ella todos los que se salvarán por los méritos de Cristo, es decir desde del justo Abel hasta el último de los predestinados; b) social, y en este sentido pertenecen a la Iglesia sólo los bautizados en Cristo que siguen unidos a la Madre Católica". La Asamblea conciliar, en la Constitución dogmática Lumen gentium ha expuesto maravillosamente el alcance de la gracia redentora para todos los hombres de buena voluntad.

Estas cinco ponencias relatadas, con sus diálogos esclarecedores, fueron lo importante de las sesiones, lo que despertó interés en los asambleistas y lo que produjo un impacto inquietante. Las otras ponencias, más bien de tipo informativo, contribuyeron a redondear las jornadas. Entre estas últimas aportaciones destaquemos la charla enviada por el profesor Jedin, Imagen católica de Lutero en su evolución bistórica. Según el profesor Jedin, la imagen católica ha sido considenada de diversos modos a través de la historia. Desde la primera biografía aparecida en 1549 en que Lutero aparece como un auténtiço heresiarca que lanza a la cristiandad a una bancarrota hasta las obras más recientes, en aligunas de las cuales se intenta revalorizar excesivamente al monje reformador, los historiadores c investigadores han ido mostrando diversas facetas del ser y del quehacer lute- 
rano. Actualmente se hacen notar dos posturas extremas sobre Lutero: el reformador heresiarca expulsado de la Iglesia y el Lutero demasiado benévolamente considerado por algunos católicos. El peligro de esta última postura consiste en un afán, imposible hoy, de hacer católico a Lutero. No obstante la tesis admitida en nuestros días es la de un Lutero eminentemente religioso que intenta penetrar la esencia del Cristianismo. No fue él sólo el causante de la escisión. Tampoco fue Lutero un destructor dañino e intencionado. Su ilusión primera era estupenda, pero las circunstancias fueron calamitosas. La conclusión de Jedin es: estudiar a Lutero para ver lo bueno que tiene, no acentuar la maldad de las circunstancias ambientales, saber distinguir entre el Lutero teólogo y pensador y el Lutero político enmarcado en una estructura concreta.

El profesor García Suárez, de Pamplona, en su charla amena y ligera: El Vaticano y la Reforma trata de presentar el Vaticano II como una respuesta a los Reformadores. Los puntos en que centra su disertación son los siguientes: Vaticano II como respuesta a los Reformadores que acusan a la Iglesia de impedir el contacto personal con Dios; Vaticano II como respuesta a la ofensiva protestante de que da jerarquía abarca todo el sacerdocio de los fieles; Vaticano II como respuesta a la afirmación protestante de que el ministerio jeránquico católico abarca todo el sacerdocio de los fieles, y Vaticano II como respuesta a la acusación protestante sobre el racionalismo católico. Laudable el afán del conferenciante y el tono cálido que supo dar a sus palabras.

Las jornadas terminaron el día 21 de abril. Como frutos maduros podemos mencionar los siguientes: el diálogo ecuménico establecido, diálogo interior con pastores protestantes españoles y diálogo exterior con teólogos de Centroeuropa e Hispanoamérica. Se recalicó la necesidad de una colaboración ecuménica más intensa en España, urgente ronovación ecuménica de la enseñanza teológica, conveniencia de una más amplia difusión del espíritu ecuménico a través de los medios de comunicación social, puesta en marcha de un laboratorio de noticias ecuménicas en relación con las gnandes agencias de prensa, tevisión de los textos de religión e historia que van apareciendo. Quedó aprobada también la publicación de una revista mensual titulada Renovación ecuménica de caráoter popular.

Nos queda, por fin, felicitar sinceramente al centro Juan XXIII de Salamanca a la vez que hacemos una llamada al estudio y a la reflexión teológica a cuantos están empeñados en la común tarea de la renovación conciliar. Solamente cuando la teología oriente de hecho y plenamente la acción pastoral comenzará el Concilio a producir sus frutos. Esta postura lleva consigo, como se hizon notar en las Jornadas, la aceptación de un sacrificio grande y de un enorme trabajo de maduración interior mediante la meditación y el estudio.

A. GARRIDO SANZ 